\title{
ANALISIS KUALITAS SISTEM INFORMASI KEGIATAN SEKOLAH BERBASIS MOBILE WEB DI SMK NEGERI 2 YOGYAKARTA
}

\author{
Taufiq Abdul Ghaffur \& Nurkhamid \\ Universitas Negeri Yogyakarta \\ e-mail: taufiqabdulghaffur@gmail.com
}

\begin{abstract}
The purpose of this study is to ensure the quality of mobile web-based school activity information system to avoid errors and to ensure the feature and functionality as proposed by testing using ISO 25010 standard. Testing was conducted using 4 characteristics of the ISO 25010 that are functional suitability, compatibility, usability, and performance efficiency. The instrument used are black-box testing, USE questionnaire, Yslow tools, and Pingdom Website Speed Test. The result of this research are the information system was meet the ISO 25010 standard with functional suitability characteristic is $100 \%$ (very high), compatibility characteristic is 100\%, usability characteristic is $82 \%$ with the value of alpha cronbach is 0,981 (excellent), and performance efficiency characteristic obtained using the average value of overall performance score of 94.2 and average access speed of 0,9305 second each page (good).
\end{abstract}

Keywords: quality of information system, ISO 25010

\begin{abstract}
ABSTRAK
Tujuan dari penelitian ini adalah menjamin tingkat kualitas Sistem Informasi Kegiatan Sekolah berbasis mobile web agar tidak terjadi error serta fitur dan fugsionalitasnya sesuai yang dijanjikan dengan melakukan pengujian menggunakan standar ISO 25010. Pengujian dilakukan menggunakan 4 karakteristik pada standar ISO 25010 yaitu functional suitability, compatibility, usability, dan performance efficiency. Instrumen yang digunakan yaitu black-box testing, USE Questionnaire, Yslow tools dan Pingdom Website Speed Test. Hasil dari penelitian ini adalah Sistem Informasi Kegiatan Sekolah telah memenuhi standar ISO 25010 pada karakteristik functional suitability dengan nilai 100\% (sangat tinggi), karakteristik compatibility sebesar 100\%, karakteristik usability sebesar $82 \%$ dengan nilai alpha cronbach sebesar 0.981 (sempurna), dan karakteristik performance efficiency diperoleh nilai rata-rata overall performance score 94.2 dan rata-rata kecepatan akses sebesar 0.9305 detik setiap halaman (baik).
\end{abstract}

Kata kunci: kualitas sistem informasi, ISO 25010

\section{PENDAHULUAN}

Menurut Satzinger, Jackson, \& Burd (2010) Sistem informasi adalah sekumpulan komponen terkait yang mengumpulkan, memproses, menyimpan, dan menyediakan informasi yang dibutuhkan untuk menyelesaikan tugas bisnis. Sistem informasi berfungsi untuk menyediakan informasi yang sesuai dan akurat kepada para pengguna pada saat yang tepat.Implementasi sistem informasi sangat membantu dalam menyelesaikan masalah-masalah penyediaan informasi dibanding menggunakan cara manual (Riyanto, 2011:73).

Sistem Informasi Kegiatan Sekolah berbasis mobile web merupakan sistem informasi yang berfungsi untuk mempermudah penyebaran informasi terkait kegiatan sekolah bagi siswa di SMK Negeri 2 Yogyakarta. Melalui Sistem Informasi Kegiatan Sekolah ini siswa dapat mengakses informasi terkait kegiatan sekolah seperti berita, agenda dan pesan yang dikelola bagian bagian kesiswaan. Sistem ini berfungsi menggantikan kumpulan berkas dengan sistem basis data komputer 
yang mampu diterapkan di perangkat komputer manapun dan juga dapat diakses oleh seluruh siswa dengan mudah melalui smartphone. Sistem ini dikelola oleh bagian kesiswaan sehingga dapat menampilkan informasi lengkap terkait kegiatan sekolah.

Menurut Crosbi dalam (Sommervillle, 2003: 174) yang berpendapat bahwa perangkat lunak yang dikembangkan harus sesuai dengan kebutuhan dan spesifikasi penggunannya. Pengukuran kualitas perangkat lunak dapat dilakukan dengan menggunakan berbagai macam model. Dari berbagai macam model salah satunya adalah ISO 25010. Model ISO 25010 merupakan standar internasional yang berlaku saat ini. Model ini menentukan delapan karakteristik termasuk functional suitability, reliability, performance efficiency, usability, maintainability, security, compability, dan portability yang dibagi lagi menjadi serangkaian sub-karakteristik (Wagner, 2013).

Menurut David (2011), pengujian untuk mobile application meliputi empat karakteristik yaitu functional testing, compatibility testing, usability testing, dan performance testing. Jika standar kualitas mobile web David dibandingkan dengan standar ISO 25010 maka pengujian sebuah aplikasi web perlu dilakukan pada karakteristik functional suitability, compatibility, usability, dan performance efficiency.

Functional suitability bertujuan untuk memastikan bahwa program telah berjalan sesuai dengan skenario dan menghasilkan keluaran yang sesuai sebagai reaksi dari suatu aksi tertentu. Karakteristik ini terdari dari subkarakteristik yaitu functional completeness functional correctness, dan functional appropriateness. Compatibility merupakan kemampuan dari dua atau lebih komponen perangkat lunak untuk dapat melakukan pertukaran informasi dan melakukan fungsi yang dibutuhkan ketika digunakan pada hardware atau lingkungan perangkat lunak yang sama. Usability merupakan karakteristik sejauh mana sebuah produk atau sistem dapat digunakan oleh pengguna tertentu untuk mencapai tujuan efektif, efisien, dan kepuasan dalam konteks pengguna. Performance efficiency merupakan tingkat kinerja penggunaan memory atau CPU, konsumsi baterai, dan mengambil data dalam server di bawah kondisi tertentu.

Berdasarkan permasalahan di atas maka penelitian ini dilakukan dengan tujuan untuk menjamin kualitas Sistem Informasi Kegiatan Sekolah agar tidak terjadi error serta fitur dan fungsionalitasnya sesuai yang dijanjikan menggunakan standar ISO 25010. Pengujian menggunakan karakteristik functional suitability, compatibility, usability, dan performance efficiency.

\section{METODE}

Penelitian "Analisis Kualitas Sistem Informasi Kegiatan Sekolah berbasis Mobile Web di SMK Negeri 2 Yogyakarta" adalah penelitian kuantitatif. Menurut Sugiyono (2013: 13) penelitian kuantitatif adalah penelitian yang berlandaskan pada filsafat positivisme, digunakan untuk meneliti pada populasi atau sampel tertentu, pengumpulan data menggunakan instrumen penelitian, analisis data bersifat kuantitatif/statistik, dengan tujuan untuk menguji hipotessi yang telah diteteapkan. Penelitian "Analisis Kualitas Sistem Informasi Kegiatan Sekolah berbasis Mobile Web di SMK Negeri 2 Yogyakarta" dilakukan pada bulan Desember 2016 Februari 2017. Lokasi penelitian di SMK Negeri 2 Yogyakarta. Subjek penelitian pada karakteristik functional suitability yaitu 2 responden ahli pemrograman (programmerl developer). Subjek penelitian pada karakteristik usability menggunakan 20 responden yang terdiri siswa dari berbagai jurusan. Menurut Nielsen (2012), jumlah responden untuk menguji usability minimal menggunakan 20 orang. Sedangkan karakteristik compatibility, dan performance efficiency menggunakan Sistem Informasi Kegiatan Sekolah sebagai subjek penelitian. 
Prosedur untuk melakukan pengujian Sistem Informasi Kegiatan Sekolah adalah sebagai berikut: (1) Functional Suitability yaitu ahli dalam bidang web dan mobile developer mengisi kuesioner berupa checklist semua fungsi Sistem Informasi Kegiatan Sekolah; (2) Compatibility yaitu Sistem Informasi Kegiatan Sekolah dijalankan di berbagai jenis platform perangkat mobile, meliputi versi OS dan resolusi layar; (3) Usability yaitu siswa mengisi kuesioner (USE Questionnaire) yang terdiri dari 30 pertanyaan yang teruji validitasnya; dan (4) Performance Efficiency yaitu Sistem Informasi Kegiatan Sekolah dianalisis menggunakan YSlow yang menghasilkan overall performance score yang meliputi content, cookie, css, images, javascript, dan server. Penggunaan Pingdom Website Speed Test digunakan untuk menguji kecepatan loading suatu website.

Teknik pengumpulan data yang digunakan dalam penelitian ini yaitu wawancara, observasi, dan kuesioner. Wawancara digunakan untuk mengumpulkan informasi pada tahap perencanaan dengan tujuam untuk mendefinisikan dan menganalisis kebutuhan perangkat lunak yang akan dikembangkan. Observasi dilakukan untuk membantu proses analisis kebutuhan dan pengumpulan data pada proses pengujian pada karakteristik performance efficiency, functional suitability, \& compatibility.

Pengujian functional suitability menggunakan metode black-box testing yang dilakukan oleh ahli dalam bidang web dan mobile developer. Pengujian dilakukan dengan mengisi kuesioner berupa checklist semua fungsi Sistem Informasi Kegiatan Sekolah. Instrumen functional suitability memiliki 3 subkarakteristik yaitu functional correctness terdiri dari 10 pertanyaan, functional correctness terdiri dari 10 pernyataan, dan functional appropriateness terdiri dari 4 pernyataan.

Pengujian dilakukan dengan menjalankan Sistem Informasi Kegiatan Sekolah pada berbagai macam perangkat smartphone dengan relosulusi layar berbeda dan sistem operasi Android yang paling banyak digunakan pengguna yaitu Jelly Bean, KitKat, Lollipop, dan Marshmallow menurut hasil survey data pengguna android berdasarkan versi platform yang dilakukan www.developer.android.com.

Instrumen penelitian pengujian usability menggunakan angket USE Questionnaire oleh Arnold M. Lund (2001) yang telah diterjemahkan dan dimodifikasi untuk pengujian perangkat lunak Sikatans dengan jumlah 30 pernyataan dengan 4 kriteria yaitu usefulness, ease of use, ease of learning, dan satisfaction.

Pengujian perfomance effieciency berfokus pada sub-karakteristik time behavior maka digunakan alat YSlow dan Pingdom Website Speed Test. Yslow, digunakan untuk mengukur tingkat performa dari website yang dikelompokkan pada kategori: content, cookie, css, images, javascript dan server. Selanjutnyajuga Pingdom Website Speed Test, yang merupakan menguji kecepatan loading suatu website.

Pengujian functional suitability dilakukan dengan menggunakan teknik analisis deskriptif, yaitu menganalisis persentase hasil pengujian setiap fungsi aplikasi oleh ahli pemrograman (programmer/developer) di bidang web mobile developer. Skala yang digunakan dalam pengujian ini adalah skala Guttman. Kemudian persentase kelyakan didapat dengan menggunakan perhitungan sebagai berikut:

Persentase $=\frac{\text { Skor yang didapatkan }}{\text { Skor Maksimal }} \times 100 \%$

Hasil perhitungan kemudian dikonversi menjadi pernyataan predikat (Guritno, Sudaryono, \& Raharja, 2011) dengan sedikit modifikasi istilah predikat yang digunakan. Pembagian kategori kelayakan yang telah dimodifikasi dapat dilihat pada Tabel 1. 
Tabel 1. Interprestasi Presentasi

\begin{tabular}{ccc}
\hline No. & Persentase & Interpretasi \\
\hline 1. & $0 \%-20 \%$ & Sangat Buruk \\
2. & $21 \%-40 \%$ & Buruk \\
3. & $41 \%-60 \%$ & Cukup \\
4. & $61 \%-80 \%$ & Baik \\
5. & $81 \%-100 \%$ & Sangat Baik \\
\hline
\end{tabular}

Pengujian dilakukan dengan menjalankan Sistem Informasi Kegiatan Sekolah pada berbagai macam perangkat smartphone dengan relosulusi layar dan versi platform berbeda. Sistem operasi Android yang dipilih sesuai dengan hasil survey OS yang paling banyak digunakan pengguna yaitu Jelly Bean, KitKat, Lollipop, dan Marshmallow. Selanjutnya dilakukan perhitungan skor persentase hasil pengujian dan dicocokkan dengan skala penilaian untuk mengetahui tingkat kualitas aspek compatibility aplikasi dengan rumus:

Persentase $=\frac{\text { Skor yang didapatkan }}{\text { Skor Maksimal }} \times 100 \%$

Pengujian usability menggunakan skala Liker dengan skala 7 dengan rincian jawaban Sangat Sangat Setuju (SSS) diberi skor 7, Sangat Setuju (SS) diberi skor 6, Setuju (S) diberi skor 5, Ragu-Ragu (R) diberi skor 4, Tidak Setuju (TS) diberi skor 3, Sangat Tidak Setuju (STS) diberi skor 2, dan Sangat Sangat Tidak Setuju (SSTS) diberi skor 1. Berikut rumus perhitungan skor pengujian usability:

$$
\begin{aligned}
\text { Skor }_{\text {total }}= & \left(\mathrm{J}_{\text {SSS }} \times 7\right)+\left(\mathrm{J}_{\text {SS }} \times 6\right)+\left(\mathrm{J}_{\mathrm{S}} \times 5\right)+ \\
& \left(\mathrm{J}_{\mathrm{R}} \times 4\right)+\left(\mathrm{J}_{\mathrm{TS}} \times 3\right)+\left(\mathrm{J}_{\text {STS }} \times 2\right) \\
& +\left(\mathrm{J}_{\text {SSTS }} \times 1\right)
\end{aligned}
$$

Keterangan:

$$
\begin{aligned}
\mathrm{J}_{\mathrm{SSS}}= & \text { Jumlah responden menjawab } \\
& \text { Sangat Sangat Setuju } \\
\mathrm{J}_{\mathrm{SS}}= & \text { Jumlah responden menjawab } \\
& \text { Sangat Setuju } \\
\mathrm{J}_{\mathrm{S}}= & \text { Jumlah responden menjawab } \\
& \text { Setuju } \\
\mathrm{J}_{\mathrm{R}}= & \text { Jumlah responden menjawab Ragu } \\
& - \text { Ragu }
\end{aligned}
$$

$$
\begin{aligned}
\mathrm{J}_{\mathrm{TS}}= & \text { Jumlah responden menjawab Tidak } \\
& \text { Setuju } \\
\mathrm{J}_{\mathrm{STS}}= & \text { Jumlah responden menjawab } \\
& \text { Sangat Tidak Setuju } \\
\mathrm{J}_{\mathrm{SSTS}}= & \text { Jumlah responden menjawab } \\
& \text { Sangat Sangat Tidak Setuju }
\end{aligned}
$$

Kemudian mencari untuk mendapatkan kriteria interpretasi persentase hasil pengujian usability dengan rumus:

$$
\text { Persentase }=\frac{\text { Skor total }}{i \times r \times 7} \times 100 \%
$$

Keterangan:

$$
\begin{array}{lll}
\text { Skor total } & =\text { skor total hasil jawaban } \\
& \text { responden } \\
\mathrm{i} & =\text { jumlah pertanyaan } \\
\mathrm{r} & =\text { jumlah responden }
\end{array}
$$

Kemudian dari hasil yang didapat menggunakan kuesioner di atas maka dilakukan perhitungan konsistensi atau reliabilitas terhadap instrumen. Perhitungan Alpha Cronbach dihitung menggunakan software SPSS dengan interpretasi nilai Alpha Cronbach yang tersaji pada Tabel 2 (Gliem \& Gliem, 2013).

Tabel 2. Nilai Konsistensi Alpha Cronbach

\begin{tabular}{ccc}
\hline No. & $\begin{array}{c}\text { Persentase } \\
\text { Pencapaian }\end{array}$ & Interpretasi \\
\hline 1. & $\mathrm{r}_{11} \geq 0,9$ & Sempurna \\
2. & $0,9>\mathrm{r}_{11} \geq 0,8$ & Baik \\
3. & $0,8>\mathrm{r}_{11} \geq 0,7$ & Dapat Diterima \\
4. & $0,7>\mathrm{r}_{11} \geq 0,6$ & Diragukan \\
5. & $0,6>\mathrm{r}_{11} \geq 0,5$ & Buruk \\
6 & $\mathrm{r}_{11}<0,5$ & Tidak Dapat \\
& & Diterima \\
\hline
\end{tabular}

Pengujian ini menggunakan parameter dari YSlow. Analisis aspek perfomance efficiency dilakukan dengan melihat hasil pengujian dari YSlow pada komponen besarnya bytes data dokumen, jumlah HTTP request dan score/grade akhir. 
Tabel 3. YSlow Grade

\begin{tabular}{ccc}
\hline No. & Score & Grade \\
\hline 1. & $90-100$ & $\mathrm{~A}$ \\
2. & $80-89$ & $\mathrm{~B}$ \\
3. & $70-79$ & $\mathrm{C}$ \\
4. & $<69$ & $\mathrm{D}$ \\
\hline
\end{tabular}

Sedangkan pengujian menggunakan alat Pingdom Website Speed Test akan menghasilkan nilai dalam satuan detik. Analisis kecepatan respon dan akses dari web digunakan interpretasi dari J. Nielsen yang dikutip oleh Nah (2004) ditunjukkan dalam Tabel 4.

Tabel 4. Tiga Batasan Waktu Respon dari Komputer

\begin{tabular}{|c|c|c|}
\hline No. & Waktu & Respon \\
\hline 1. & 0.1 detik & $\begin{array}{l}\text { Pengguna menerima } \\
\text { respon dari perintah yang } \\
\text { dijalankan }\end{array}$ \\
\hline 2. & 1.0 detik & $\begin{array}{l}\text { Batasan dari pengguna } \\
\text { berfikir untuk menunggu } \\
\text { feedback dari sistem }\end{array}$ \\
\hline 3. & 10 detik & $\begin{array}{lr}\text { Batasan akhir perhatian } \\
\text { pengguna } \\
\text { menunggu sistem }\end{array}$ \\
\hline
\end{tabular}

\section{HASIL}

Pengujian aspek functional suitability ini dilakukan dengan menggunakan kuisioner berupa checklist semua fungsi dalam sistem yang dilakukan oleh ahli sebanyak 2 orang. Ahli yang pertama berasal dari guru SMKN 2 Yogyakarta yang berpengalaman dalam bidang Web maupun teknologi informasi sedangkan ahli yang kedua berasal dari programmer Mil System yang bergerak dibidang pengembangan aplikasi berbasis web dan mobile developer. Berikut perhitungan pengujian functional suitability:

$$
\begin{aligned}
\text { Persentase } & =\frac{\text { Skor yang didapatkan }}{\text { Skor Maksimal }} \times 100 \% \\
\text { Persentase } & =\frac{48}{48} \times 100 \%=100 \%
\end{aligned}
$$

Berdasarkan hasil pengujian functional suitability di atas, maka diperoleh persentase $100 \%$. Nilai tersebut kemudian dikonversi menjadi pernyataan predikat sehingga menunjukkan kualitas perangkat lunak dari sisi functional suitability bahwa dinyatakan "Sangat Tinggi".

Pengujian aspek compatibility dilakukan dengan menguji aplikasi di berbagai jenis platform perangkat mobile, meliputi versi OS dan resolusi layar yang berbeda. Perangkat yang digunakan untuk melakukan pengujian ini adalah smartphone berbasis Android dengan sistem operasi yang paling banyak digunakan pengguna yaitu Jelly Bean, KitKat, Lollipop, dan Marshmallow. Adapun tabel hasil dan dokumentasi pengujian compatibility berdasarkan jenis perangkat dapat dilihat pada tabel berikut:

\begin{tabular}{|c|c|c|c|}
\hline Perangkat & OS & Layar (Pixels) & Hasil \\
\hline 1. Evercoss A74 & Jelly Bean 4.2.2 & $480 \times 800$ & $\begin{array}{l}\text { Berjalan baik tanpa ada pesan } \\
\text { kesalahan }\end{array}$ \\
\hline 2. Samsung Galaxy S5 & Kitkat 4.4.2 & $1080 \times 1920$ & $\begin{array}{l}\text { Berjalan baik tanpa ada pesan } \\
\text { kesalahan }\end{array}$ \\
\hline 3. Xiaomi Redmi 3 Pro & Lollipop 5.1 & $720 \times 1280$ & $\begin{array}{l}\text { Berjalan baik tanpa ada pesan } \\
\text { kesalahan }\end{array}$ \\
\hline 4. Zenpad 8.0 Z380 KL & Marshmallow 6.0 & $800 \times 1280$ & $\begin{array}{l}\text { Berjalan baik tanpa ada pesan } \\
\text { kesalahan }\end{array}$ \\
\hline
\end{tabular}

Tabel 5. Hasil Pengujian Compatibility 
Dari hasil pengujian pada Tabel 5 dapat dilakukan perhitungan persentase sebagai berikut :

Persentase $=\frac{11}{11} \times 100 \%=100 \%$

Pengujian usability diperoleh hasil jawaban Sangat Sangat Setuju (SSS) berjumlah 191, Sangat Setuju (SS) berjumlah 191, Setuju (S) berjumlah 126, Ragu-Ragu (R) berjumlah 62, Tidak Setuju (TS) berjumlah 19, Sangat Tidak Setuju (STS) berjumlah 5, Sangat Sangat dan Tidak Setuju (SSTS) berjumlah 6. Hasil pengujian usability dihitung menggunakan rumus sebagai berikut:

$$
\begin{aligned}
\text { Skor }_{\text {total }}= & (191 \times 7)+(191 \times 6)+(126 \times 5)+ \\
& (62 \times 4)+(19 \times 3)+(6 \times 2) \\
& +(5 \times 1) \\
= & 3435
\end{aligned}
$$

Persentase $=3435 / 4200 \times 100 \%=82 \%$

Selanjutnya dilakukan perhitungan untuk mencari reliabilitas kuesioner dan mencari persentase pengujian aspek usability.
Perhitungan reliabilitas usability dengan koefisien Alpha Cronbach menggunakan software SPSS. Hasil perhitungannya dapat dilihat pada Gambar 1.

Case Processing Summary

\begin{tabular}{|ll|r|r|}
\hline & \multicolumn{1}{|c|}{$N$} & \multicolumn{1}{c|}{$\%$} \\
\hline Cases & Valid & 20 & 100.0 \\
& Excluded & 0 & .0 \\
& Total & 20 & 100.0 \\
\hline
\end{tabular}

a. Listwise deletion based on all variables in the procedure.

\section{Reliability Statistics}

\begin{tabular}{|r|r|}
\hline $\begin{array}{c}\text { Cronbach's } \\
\text { Alpha }\end{array}$ & N of ltems \\
\hline .981 & 30 \\
\hline
\end{tabular}

Gambar 1. Hasil Perhitungan Alpha Cronbach dengan SPSS

Perhitungan alpha cronbach diperoleh hasil 0,981 kemudian dibandingkan dengan Tabel 2 sehingga dinyatakan sempurna. Pengujian performance efficiency dilakukan pada setiap halaman Sistem Informasi Kegiatan Sekolah. Hasil pengujian performance efficiency tersaji pada Tabel 6.

Tabel 6. Hasil Pengujian Performance Efficiency

\begin{tabular}{cccc}
\hline Halaman & $\begin{array}{c}\text { Page Load } \\
\text { Time (detik) }\end{array}$ & $\begin{array}{c}\text { Overall Performance } \\
\text { Score }\end{array}$ & $\begin{array}{c}\text { Max } \\
\text { Score }\end{array}$ \\
\hline Login & 0.912 & 97 & 100 \\
Sign up & 0.916 & 97 & 100 \\
Home & 0.949 & 93 & 100 \\
Beranda & 0.908 & 94 & 100 \\
Detail Berita & 1 & 93 & 100 \\
Pesan & 0.86 & 94 & 100 \\
Baca Pesan & 0.957 & 94 & 100 \\
Agenda & 0.951 & 94 & 100 \\
Profil Siswa & 0.929 & 93 & 100 \\
Tentang Sikatans & 0.923 & 93 & 100 \\
\hline Rata-rata & $\mathbf{0 . 9 3 0 5}$ & $\mathbf{9 4 . 2}$ & $\mathbf{1 0 0}$ \\
\hline
\end{tabular}


Dengan demikian hasil pengujian performance efficiency dengan menggunakan YSlow menunjukkan rata-rata overall performance score sebesar 94.2 kemudian dibandingkan dengan Tabel 3 maka menunjukkan grade A dan didapat kecepatan akses menggunakan Pingdom Website Speed Test dengan rata-rata 0.9305 detik setiap halaman. Web dikatakan baik apabila waktu load setidaknya kurang dari 10 detik (Nielsen, 2010). Sehingga dapat disimpulkan Sistem Informasi Kegiatan Sekolah telah memenuhi karakteristik performance efficiency.

\section{SIMPULAN}

Berdasarkan hasil penelitian, peneliti menyimpulkan bahwa Sistem Informasi Kegiatan Sekolah berbasis mobile web di SMK Negeri 2 Yogyakarta telah memenuhi standarkualitas ISO 25010. Pada karakteristik functional suitability sebesar $100 \%$ (sangat tinggi), karakteristik campatibility sebesar $100 \%$, karakteristik usability sebesar $82 \%$ dan nilai alpha cronbach sebesar 0,981 (sempurna), karakteristik performance efficiency nilai ratarata overall performance score sebesar 94,2 sehingga termasuk kategori grade A dan ratarata kecepatan akses setiap halaman sebesar 0,9305 detik (baik). Untuk penelitian lebih lanjut, terdapat saran untuk menggunakan teknik pengujian kualitas perangkat lunak yang lebih beragam dan mengembangkan metode agar lebih dapat mengungkap kualitas perangkat dan memberikan rekomendasi dari hasil penilaian secara global.

\section{DAFTAR PUSTAKA}

Android Developers. 2017. The relative number of devices running a given version of the android platform. Diakses tanggal 7 Februari 2017 dari https://developer.android.com/about/da shboards/index.html
David, A.B. 2011. Mobile application testing: best practices to ensure quality. AMDOCS. Diakses pada tanggal 23 Januari 2017 dari http://www.globaltelecombusiness.com/ pdf/AMDOCS\%20WHITEPAPER_\%2 0Mobile\%20application\%20testing\%20 whitepaper.pdf

Guritno, Suryo., Sudaryono \&Raharja Untung. 2011. Theory and apllication of IT research: Metodologi Penelitian Teknologi Informasi. Yogyakarta: Penerbit ANDI

Gliem, J.A. \& Gliem, R.R. 2003. Calculating, interpreting and reporting cronbach's alpha reliability coefficient for likerttype scales. Midwest research to practice conference in adult, continuing and community education. Diakses pada tanggal 16 Januari 2017 dari https://scholarworks.iupui.edu/bitstream /handle/1805/344/Gliem\%20\%\%20Glie m.pdf?.

Lund, A.M. 2001. Measuring usability with the USE Questionnaire. Usability and user experience SIG. Diakses pada tanggal 16 Januari 2017 dari https://www.researchgate.net/publicatio n/230786746_Measuring_Usability_wit h_the_USE_Questionnaire

Nah, H. F. - H. 2004. A study on tolerable waiting time: how long are web users willing to wait?. College of Business administration university of NebraskaLincoln.

Nielsen, J. 2010. Website response times. Diakses pada tanggal 20 Januari 2017 dari https://www.nngroup.com/articles/ website-response-times

Nielsen, Jakob. 2012. How many test users in a usability study? Diakses pada tanggal 20 Januari $2017 \quad$ dari https://www.nngroup.com/articles/howmany-test-users/ 
Satzinger, J., Jackson, R., \& Burd, S. 2010. Systems analysis and design in a changing world. $5^{\text {th }}$ ed. Boston: Course Technology

Sommerville, I. 2003. Software engineering/ Sixth Edition. (Z. Hanun, Trans.) Jakarta: Erlangga.
Sugiyono. 2013. Metode penelitian pendidikan: pendekatan kuantitatif, kualitatiffan R\&D. Bandung: Alfabeta

Wagner, S. 2103. Softwareproduct quality control. Newyork: Springer-Verlag Berlin Heidelberg. 